\title{
Effect of a preauthorization policy on the utilization rate of after-hours emergency department neuroradiology computed tomography
}

\author{
Deljit Dhanoa, BASc, MD, MBA, DABR*; Kirsteen Rennie Burton, MSc, MBA, MD*; Lyne Noël de \\ Tilly, MD*; Ravi J. Menezes, PhD
}

\section{ABSTRACT}

Objective: To evaluate the impact of an emergency department (ED) automatic preauthorization policy on after-hours utilization of neuroradiology computed tomography (CT).

Methods: All CT studies of the head with contrast facial bones, orbits, spine, and neck requested through the ED and performed between January 1, 2004, and December 31, 2010, were reviewed. The preauthorization policy was instituted on February 25, 2008. A control group of noncontrast CT head studies was used for comparison. Pre- and postpolicy implementation utilization rates were compared between the control group of noncontrast CT head studies and the study group neuroradiology CT studies.

Results: During the study period, 408,501 ED patient visits occurred and 20,703 neuroradiology CT studies were carried out. The pre- and postimplementation groups of noncontrast CT head scans totalled 7,474 and 6,094, respectively, whereas the pre- and postimplementation groups of all other neuroradiology CT studies totalled 3,833 and 3,302 , respectively. The CT utilization between the two groups did not differ significantly: the noncontrast head group pre- and postpolicy implementation increased by 0.31 to $3.41 \%$, whereas the utilization of all other neuroradiology CT studies increased by 0.22 to $1.84 \%$ ( $p$ value $=0.061$ for a difference between groups) . Conclusion: Implementation of an automatic preauthorization policy for after-hours neuroradiology CT studies did not result in a statistically significant increase in CT utilization. This suggests that concerns regarding the negative effects of such policies may be unfounded, and further research in this area is warranted.

\section{RÉSUMÉ}

Objectif: L'étude visait à évaluer l'incidence d'une règle d'autorisation préalable automatique au service des urgences (SU) sur le taux de recours à la tomodensitométrie
(TDM), en neuroradiologie, après les heures normales de travail.

Méthode: Tous les examens de la tête faits par TDM avec contraste des os de la face, des orbites, de la colonne vertébrale, et du cou, demandés par le SU et effectués du 1er janvier 2004 au 31 décembre 2010 ont été revus. La règle d'autorisation préalable est entrée en vigueur le 25 février 2008. Un groupe témoin d'imagerie de la tête par TDM sans contraste a servi d'ensemble de référence. II y a eu comparaison des taux de recours à la TDM, avant et après l'entrée en vigueur de la règle, entre le groupe témoin d'imagerie de la tête par TDM sans contraste et le groupe à l'étude d'imagerie par TDM, en neuroradiologie.

Résultats: Au cours de la période à l'étude, il y a eu 408,501 consultations au SU, et 20,703 examens ont été effectués par TDM, en neuroradiologie. Le nombre total d'examens de la tête par TDM sans contraste, effectués dans les groupes avant et après l'entrée en vigueur de la règle s'élevait à 7,474 et à 6,094 , respectivement, tandis que le nombre total de tous les autres examens faits par TDM, en neuroradiologie, dans les groupes avant et après l'entrée en vigueur de la règle s'élevait à 3,833 et à 3,302, respectivement. II n'y avait pas d'écart significatif entre les deux groupes en ce qui concerne le taux de recours à la TDM: le taux d'examens de la tête par TDM sans contraste, avant et après l'entrée en vigueur de la règle a augmenté de 0.31 et est passé à $3.41 \%$, tandis que celui de tous les autres examens par TDM, en neuroradiologie, a augmenté de 0.22 et est passé à $1.84 \%$ (écart entre les groupes: $p=0.061$ ).

Conclusions: L'entrée en vigueur de la règle d'autorisation préalable automatique du recours à la TDM, en neuroradiologie, après les heures normales de travail ne s'est pas traduite par une augmentation statistiquement significative du taux d'utilisation. Les résultats portent à croire que les craintes relatives aux effets défavorables de ce genre de

From the *Department of Radiology, St. Michael's Hospital, University of Toronto; †Department of Medical Imaging, University of Toronto; $\ddagger$ Department of Health Policy, Management and Evaluation, University of Toronto; and §Department of Medical Imaging, University Health Network, Toronto, ON.

Correspondence to: Dr. Deljit Dhanoa, 13 Seton Park Road, Toronto, ON M3C 3Z7; dhanoad@yahoo.com.

This article has been peer reviewed. 
règle ne sont pas fondées, et ils appellent une recherche approfondie en la matière.
Keywords: computed tomography, emergency medicine, neuroradiology, radiology, utilization, utilization rate
The use of computed tomography (CT) is an essential component of modern emergency department (ED) care. In recent decades, ED CT utilization rates have increased significantly, at a level that some have suggested exceeds that required from rises in patient volume. ${ }^{1-6}$ Given our rising health care costs and the need for fiscal restraint, questions emerge regarding the suitability of preauthorization policies and their potential to increase ED CT utilization and ionizing radiation exposure.

On February 25, 2008, a policy was jointly established by the departments of Radiology and Emergency Medicine at St. Michael's Hospital, a Toronto tertiary care teaching centre, which provided preauthorization for specific types of after-hours neuroradiology CT imaging studies, specifically CT of the head with contrast, facial bones, orbits, spine, and neck. Prior to the implementation of the new policy at St. Michael's Hospital, only noncontrast CT head studies were automatically preauthorized through the ED. The preauthorization policy served as a "blanket" approval process; in contrast to what existed previously, emergency physicians were no longer required to contact a radiologist for approval of the aforementioned CT studies. The purpose of this study was to determine the effect of the preauthorization policy for after-hours ED neuroradiology CT studies on the utilization of CT.

\section{METHODS}

A retrospective review of after-hour CT studies for neuroradiology studies completed at St. Michael's Hospital between January 1, 2004, and December 31, 2010, was performed. "After hours" was defined as studies ordered between $5 \mathrm{pm}$ and 8 am on weekdays as well as during weekends and statutory holidays. Adult patients who required any of the following CT studies while in the ED were included: head with or without contrast, facial bones, orbits, cervical spine, thoracic spine, lumbar spine, and neck with or without contrast. Because noncontrast CT head study requests through the ED were preapproved prior to the new policy, these served as a control group.

The identified CT studies were divided into two groups: 1) prepolicy implementation (January 1, 2004, to February 24, 2008) and 2) postpolicy implementation
(February 25, 2008, to December 31, 2010). Total ED patient volumes were also captured, based on the number of registered visits during each study interval, defined as an individual admitted to the ED time period in question. Utilization rates were calculated for both noncontrast CT head studies and all other neuroradiology CT studies included in the preauthorization policy. Utilization rates were based on the ratio of the number of CT scans ordered per ED registered visits per year. Chi-square tests were assessed for any differences in the pre- and postimplementation ratios, and a threshold $p$ value $\leq 0.05$ was deemed to be statistically significant. Institutional ethics review board approval was not sought given the study's minimal risk nature and noninvolvement of patients.

\section{RESULTS}

A total of 20,703 neuroradiology CT studies were performed during the 6-year overall study period, and all met inclusion criteria for the study. There were a total of 408,501 ED patient visits during the overall study period. Figure 1 provides a breakdown of the study population and indicates the number of CT scans performed in each study group. Figure 2 provides the number of $\mathrm{ED}$ visits for each year of the study, and Figure 3 provides the CT studies performed by year. The number of ED patient visits increased from 54,789 in 2004 to 65,879 in 2010 (a $20.2 \%$ increase). During this same period, the total number of studied CT scans performed increased from 1,917 to 3,362 (a $75.4 \%$ increase) despite the same number of operating CT scanners and CT scan hours.

The CT utilization rates for the pre- and postpolicy implementation groups are illustrated in Figure 4 and were $1.62 \%$ and $1.84 \%$, respectively ( $p$ value $=0.326$, univariate chi-square test). The CT utilization rate for the policy-based neuroradiology CT studies increased by $0.22 \%$, in contrast to $0.31 \%$ for the control group of noncontrast CT head studies (Table $1 ; p=0.061$ for the difference between groups).

\section{DISCUSSION}

The ED is the primary source of after-hours CT utilization, and there has been mounting concern that 


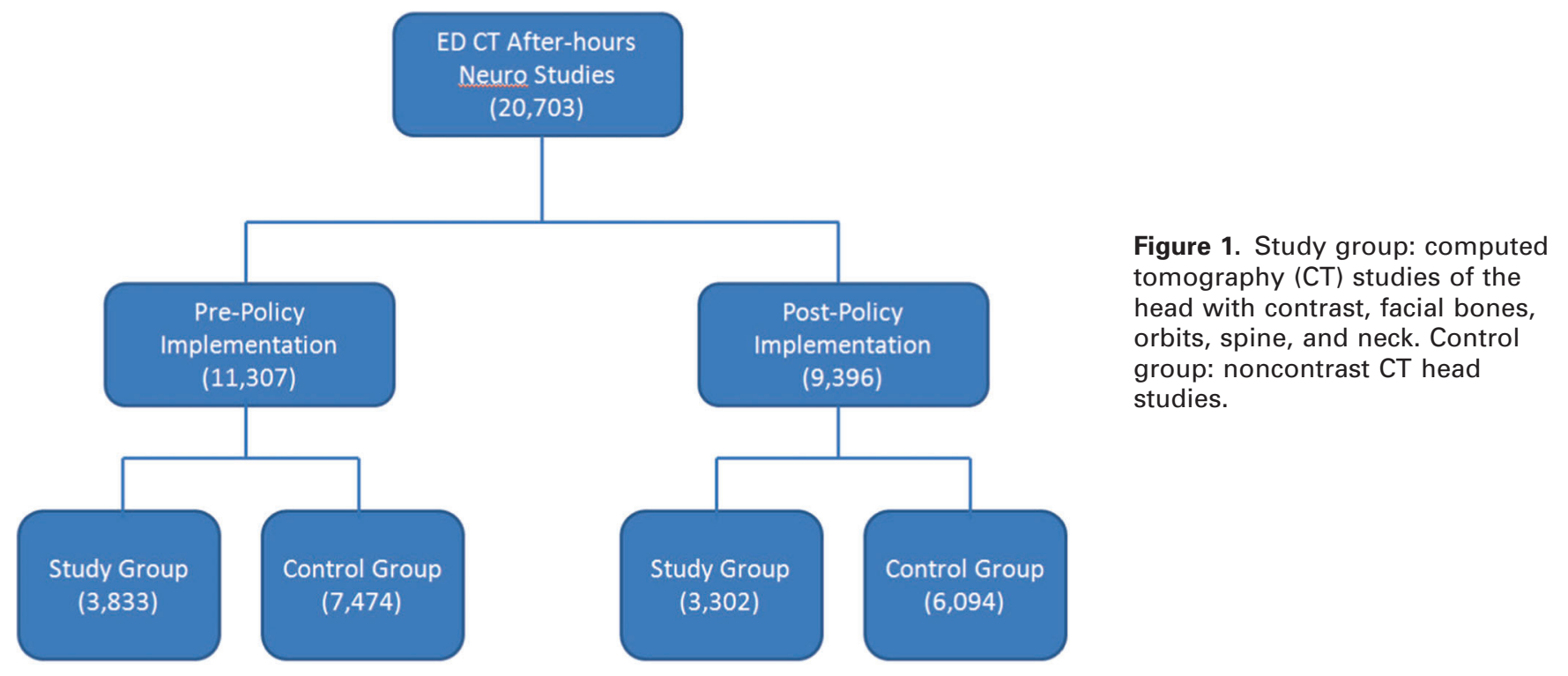

ED CT studies may be overused, resulting in unecessary patient exposure to ionizing radiation and considerable economic implications. ${ }^{7,8}$ This increasing demand for CT studies-in particular for neck and chest evaluations - has been facilitated by the widespread availability of CT scanners and their diagnostic superiority over plain radiography or other modalities. . $^{1,5,6}$

A number of suggestions have been proposed to explain the rapid observed increase in ED CT utilization at many centres. First, worsening ED congestion may pressure emergency physicians to order advanced imaging as a surrogate for more time-intensive clinical evaluation. ${ }^{9}$ Second, CT may facilitate more rapid assessment and, when needed, intervention, leading to more expeditious patient disposition from the ED. $\cdot^{10,11}$ Finally, the increased use of advanced imaging techniques, including CT, is increasingly viewed to be the standard of care for many situations, from both physician and patient perspectives. ${ }^{10}$ Given these factors, we posited that the implementation of a preauthorization neuroradiology CT policy would lead to a proliferation of ED CT utilization; however, our results indicate that this was not the case.

Our results indicate that CT utilization trends pre- and postpolicy implementation did not differ significantly. These findings contrast with those of some reports that describe a significant increase in CT utilization at some centres, one of which was over a similar time period

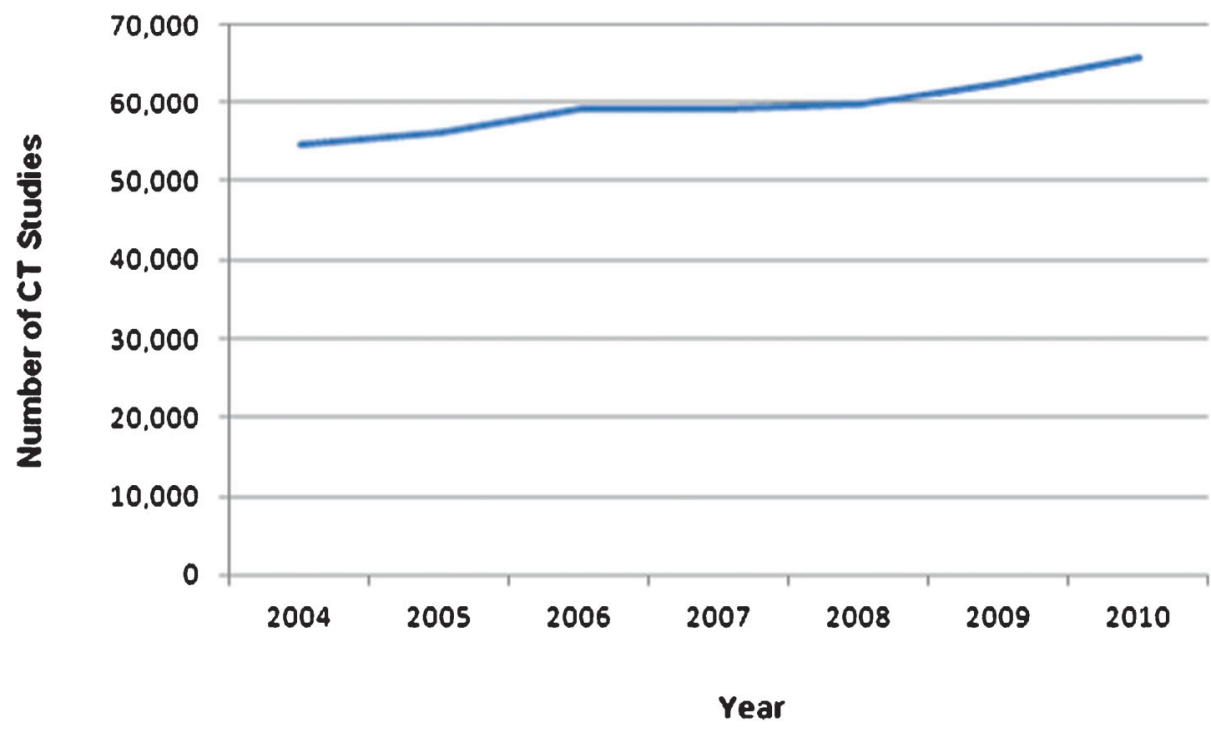

Figure 2. Annual emergency department patient volumes during the study period. 


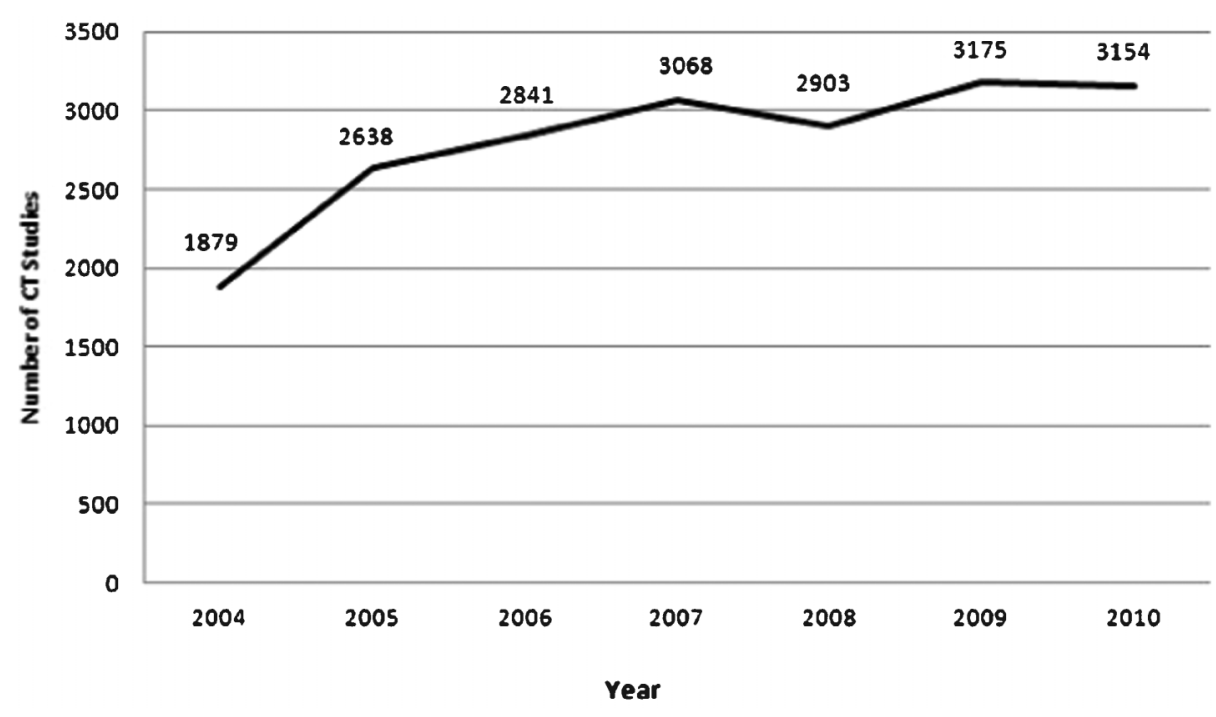

Figure 3. Number of computed tomography studies performed by year.
(2000 to 2005) but did not isolate neuroradiology CT studies and was not in the context of a pre- and postauthorization policy comparison. ${ }^{12}$ A number of other studies corroborate our findings. One group found that installation of a dedicated ED CT resulted in no significant increase in the number CT scans deemed to be unecessary. ${ }^{11}$ Another group found that the utilization of CT studies of the head increased over time within a community hospital setting but not within a tertiary hospital setting, possibly owing to differing levels of expertise and reliance on advanced imaging to facilitate patient management in different hospitals. ${ }^{9}$

Our results suggest that the implementation of a preauthorization policy for neuroradiology CT scans is not the source of an increase in after-hours CT use at a tertiary ED and, in contrast and by extension, may be an effective tool to increase ED efficiency while maintaining appropriate CT utilization. This suggestion is supported by a number of previously published analyses. One study of the appropriateness of afterhours CT head scans ordered primarily by emergency physicians found that the majority of scan orders were appropriate and led to an immediate change in the patient's medical care. ${ }^{13}$ Furthermore, these after-hours CT head scans facilitated early discharge of patients with closed head injuries or headaches. ${ }^{13}$ Although it was hypothesized that emergency physicians may order CT scans because of a fear of malpractice repercussions, in at least one survey this was not reported as being a common motivational factor. ${ }^{14}$ Although not determinable by our design, our results suggest that after-hours neuroradiology CT scans are likely being

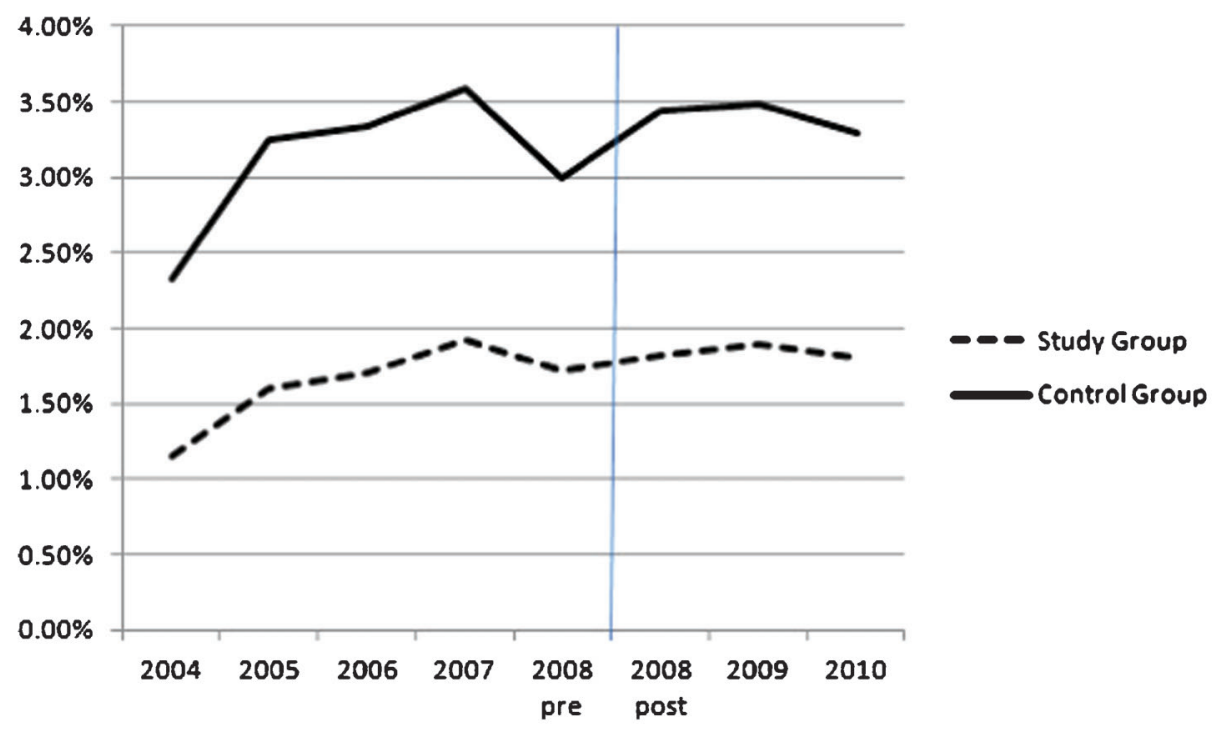

Figure 4. Computed tomography utilization rates pre- and postpolicy implementation by group. 
Neuroradiology CT utilization in the ED

Table 1. Computed tomography utilization rates pre- and postpolicy implementation

\begin{tabular}{lccc}
\hline Group & Prepolicy utilization rate & Postpolicy utilization rate & Difference pre- and postpolicy* \\
\hline Study & $1.62 \%$ & $1.84 \%$ & $0.22 \%$ \\
Control & $3.10 \%$ & $3.41 \%$ & $0.31 \%$ \\
\hline${ }^{*} p$ value $=0.061$, chi-square for the difference in utilization rates pre- and postpolicy implementation. & & \\
\hline
\end{tabular}

ordered appropriately, which may be due to the successful adoption of ED clinical decision rules, most notably the Canadian Cervical-Spine Rule (CCR) and the Canadian Computed Tomography Head Rule (CCHR). ${ }^{15}$ This hypothesis is supported by two sets of findings: 1) that awareness and use of the CCR and CCHR are highest in Canada and lowest in the United States ${ }^{16}$ and 2) that emergency physicians who work in large, academic centres are more likely to be aware of imaging decision guidelines and more likely to implement CT head scan guidelines. ${ }^{15,16}$

Our study has a number of strengths. First, it is a unique report that addresses the long-term impact of the implementation of an after-hours, preauthorization neuroradiology CT policy within the ED of a large, urban, tertiary care centre. Although one other study assessed the use of after-hours CT scans, it focused on the impact of all types of CT study results when read by residents after hours and not on the trends associated with a preauthorization ED policy. ${ }^{17}$ Second, our large sample size includes the majority of commonly requested neuroradiology CT studies that accrued over a 6-year period. Finally, as the study sample was limited to patients presenting to one $\mathrm{ED}$, any of the possible effects of different practices between hospitals were mitigated.

Our study also has a number of limitations that should be considered. We made no adjustment for patient, physician, or hospital factors, any or all of which could have influenced our findings. For example, it has been shown that awareness of ED CT use guidelines may differ between emergency physicians based on age and full-time versus part-time status. ${ }^{14}$ Additionally, as our results were generated from data from one urban academic centre, their generalizability may be limited. Imaging patterns and ED policies may differ between centres, and our findings may not be applicable to other practice settings, such as nonacademic urban or community hospitals. Examination of the pre- and postauthorization policy implementation effects at centres such as these would be informative. Although a long study time period was utilized, we did not control for changes in the prevalence of conditions that would warrant the CT imaging under study. Finally, for reasons of feasibility, we used the total number of registered ED patients as a denominator of the number of patients who would be eligible for neuroradiology imaging.

\section{CONCLUSION}

Implementation of an automatic preauthorization policy for after-hours neuroradiology CT studies did not result in a statistically significant increase in CT utilization. This suggests that concerns regarding the negative effects of such policies may be unfounded. There is likely substantial increased efficiency in the ED when emergency physicians do not require approval of specific neuroradiology CT studies, and as such, the virtues of automatic preauthorization policies should be further evaluated in various types of centres, perhaps involving other types of imaging, such as abdominal and chest CT scanning, both of which are commonly ordered from EDs during off-peak hours.

Competing interests: None declared.

\section{REFERENCES}

1. Broder J, Warshauer DM. Increasing utilization of computed tomography in the adult emergency department, 2000-2005. Emerg Radiol 2006;13:25-30, doi:10.1007/s10140-006-0493-9.

2. Broder JS. CT utilization: the emergency department perspective. Pediatr Radiol 2008;38 Suppl 4:S664-9, doi:10.1007/ s00247-008-0892-z.

3. Korley FK, Pham JC, Kirsch TD. Use of advanced radiology during visits to US emergency departments for injuryrelated conditions, 1998-2007. 7AMA 2010;304:1465-71, doi:10.1001/jama.2010.1408.

4. Bhuiya FA, Pitts SR, McCaig LF. Emergency department visits for chest pain and abdominal pain: United States, 1999-2008. NCHS Data Brief 2010;43:1-8.

5. Lee J, Kirschner J, Pawa S, et al. Computed tomography use in the adult emergency department of an academic urban hospital from 2001 to 2007. Ann Emerg Med 2010;56:591-6, doi:10.1016/j.annemergmed.2010.05.027.

6. Oguz KK, Yousem DM, Deluca T, et al. Effect of emergency department CT on neuroimaging case volume 
and positive scan rates. Acad Radiol 2002;9:1018-24, doi:10.1016/S1076-6332(03)80477-4.

7. Brenner DJ, Hall EJ. Computed tomography—an increasing source of radiation exposure. $N$ Engl 7 Med 2007;357:227784, doi:10.1056/NEJMra072149.

8. Jordan YJ, Lightfoote JB, Jordan JE. Computed tomography imaging in the management of headache in the emergency department: cost efficacy and policy implications. 7 Natl Med Assoc 2009;101:331-5.

9. Stiell IG, Clement CM, Grimshaw JM, et al. A prospective cluster-randomized trial to implement the Canadian CT Head Rule in emergency departments. CMA7 2010;182: 1527-32, doi:10.1503/cmaj.091974.

10. Heskestad B, Baardsen R, Helseth E, et al. Guideline compliance in management of minimal, mild, and moderate head injury: high frequency of noncompliance among individual physicians despite strong guideline support from clinical leaders. I Trauma 2008;65:1309-13, doi:10.1097/ TA.0b013e31815e40cd.

11. Lee KL, Graham CA, Lam JM, et al. Impact on trauma patient management of installing a computed tomography scanner in the emergency department. Injury 2009;40:873-5, doi:10.1016/j.injury.2008.12.001.
12. Wong DC, Siddle KJ. After-hours radiology. Australas Radiol 1994;38:326-30, doi:10.1111/j.1440-1673.1994.tb00211.x.

13. Ravindran V, Sennik D, Hughes RA. Appropriateness of out-of-hours CT head scans. Emerg Radiol 2007;13:181-5.

14. Wong AC, Kowalenko T, Roahen-Harrison S, et al. A survey of emergency physicians' fear of malpractice and its association with the decision to order computed tomography scans for children with minor head trauma. Pediatr Emerg Care 2011;27:182-5, doi:10.1097/PEC.0b013e31820d64f7.

15. Summerfield R, Macduff R, Davis R, et al. Comparative yield of positive brain computed tomography after implementing the NICE or SIGN head injury guidelines in two equivalent urban populations. Clin Radiol 2011;66:308-14, doi:10.1016/i.crad.2010.06.018.

16. Eagles D, Stiell IG, Clement CM, et al. International survey of emergency physicians' awareness and use of the Canadian Cervical-Spine Rule and the Canadian Computed Tomography Head Rule. Acad Emerg Med 2008;15:125661, doi:10.1111/j.1553-2712.2008.00265.x.

17. Shah NA, Hoch M, Willis A, et al. Correlation among oncall resident study volume, discrepancy rate, and turnaround time. Acad Radiol 2010;17:1190-4, doi:10.1016/j.acra.2010. 06.003 . 